\title{
Predictive diagnostic value for the clinical features accompanying intellectual disability in children with pathogenic copy number variations: a multivariate analysis
}

\author{
Elisa Caramaschi ${ }^{1+}$, llaria Stanghellini ${ }^{2 \dagger}$, Pamela Magini ${ }^{3}$, Maria Grazia Giuffrida ${ }^{4}$, Silvia Scullin ${ }^{2}$, Tiziana Giuva ${ }^{5}$, \\ Patrizia Bergonzini ${ }^{1}$, Azzurra Guerra', Paolo Paolucci ${ }^{1}$ and Antonio Percesepe ${ }^{2^{*}}$
}

\begin{abstract}
Background: Array comparative genomic hybridization (a-CGH) has become the first-tier investigation in patients with unexplained developmental delay/intellectual disability (DD/ID). Although the costs are progressively decreasing, a-CGH is still an expensive and labour-intensive technique: for this reason a definition of the categories of patients that can benefit the most of the analysis is needed. Aim of the study was to retrospectively analyze the clinical features of children with DD/ID attending the outpatient clinic of the Mother \& Child Department of the University Hospital of Modena subjected to a-CGH, to verify by uni- and multivariate analysis the independent predictors of pathogenic CNVs.

Methods: 116 patients were included in the study. Data relative to the CNVs and to the patients' clinical features were analyzed for genotype/phenotype correlations.

Results and conclusions: 27 patients (23.3\%) presented pathogenic CNVs (21 deletions, 3 duplications and 3 cases with both duplications and deletions). Univariate analysis showed a significant association of the pathogenic CNVs with the early onset of symptoms (before $1 \mathrm{yr}$ of age) and the presence of malformations and dysmorphisms. Logistic regression analysis showed a significant independent predictive value for diagnosing a pathogenic CNV for malformations $(P=0.002)$ and dysmorphisms $(P=0.023)$, suggesting that those features should address a-CGH analysis as a high-priority test for diagnosis.
\end{abstract}

Keywords: Array CGH, CNVs, Developmental delay/intellectual disability, Malformations, Multivariate analysis

\section{Background}

The use of array-CGH (a-CGH) has recently become a mainstay for the diagnosis of a broad spectrum of disorders, including developmental delay/intellectual disability (DD/ID), malformations and dysmorphisms, due to its higher resolution power (about 100-fold) and diagnostic yield (5- to 10-fold) compared with the classical karyotype [1-3]. Large scale genomic analysis have highlighted a pathogenic role for many copy number variations (CNVs), which have been detected both in cases with syndromic

\footnotetext{
*Correspondence: percesepe.antonio@unimo.it

${ }^{\dagger}$ Equal contributors

${ }^{2}$ Medical Genetics Unit, Department of Mother \& Child, University Hospital of Modena, Via del Pozzo, 71, 41124 Modena, Italy

Full list of author information is available at the end of the article
}

features and in others lacking a clinical hallmark pointing to a specific genetic condition $[4,5]$. In addition, about $12 \%$ of a healthy individual's genome can contain a copy number variation whose role, if any, remains unknown [6]. Dedicated on-line databases (DatabasE of Chromosomal Imbalance and Phenotype in Humans using Ensemble Resources - DECIPHER- http://decipher. sanger.ac.uk; Database of Genomic Variants -DGV- http:// projects.tcag.ca/variation/), continuously expanded by the scientific community, are providing growing information to perform the genotype/phenotype correlations.

Although the costs are progressively decreasing, a-CGH is still an expensive and labour- intensive technique, and as such, cost-, clinical impact- and genotype/phenotype- 
analysis have tried to define the convenience and the correct indications to perform the analysis in selected categories of patients [7]. For example, the presence of pathogenic CNVs has been correlated with a severe clinical presentation or with a pleiotropic expression of the disease $[5,8,9]$; other studies have demonstrated that the presence of at least two clinical features increases the likelihood that the phenotype is associated with CNVs [10], although many exceptions exist, which underlie the extreme phenotypic heterogeneity of genomic disorders.

To highlight the most useful indications to perform the a-CGH analysis in children with DD/ID and associated clinical features (i.e. malformations, epilepsy, dysmorphisms), we report a retrospective study based on 116 consecutive cases referred to the Department of Mother \& Child of the University Hospital of Modena. The distribution of several clinical features was studied by univariate and multivariate analysis in patients with vs. those without pathogenic CNVs, to identify the strongest predictors of the presence of genomic rearrangements and to recognize those cases in which a-CGH would be crucial for achieving the diagnosis.

\section{Methods}

\section{The clinic}

Patients have been recruited at the outpatient Pediatric Clinic of the Mother \& Child Department of the Modena University Hospital, in the years 2006-2013. The clinic receives patients across the city area (about 600,000 inhabitants) and offers second-level assistance to the Community Support Services. The outpatients are sequentially evaluated by paediatricians, paediatric neurologists and medical geneticists and their clinical information, including previous personal and familial medical history, are collected. Verification of the reported diagnosis is done through the consultation of the medical records. Patients' follow-up consists of annual clinical evaluations during which the diagnostic process is carried out by using traditional clinical and instrumental tools and genetic testing, when appropriate.

\section{The patients}

For the purposes of the study we selected consecutive paediatric patients undergoing a-CGH analysis for the presence of DD/ID associated with at least one of the following clinical features: 1) malformations, 2) epilepsy, 3) dysmorphisms. Malformations were defined as major defects (i.e. those affecting organs like the heart, the urogenital tract), whereas isolated minor congenital anomalies (i.e. persistent foramen ovale) were not considered for the purposes of the study.

Clinical and genetic data obtained were retrospectively collected in an Excel format database, including patient's records, pregnancy, neonatal and family histories, body measurements, neurologic examination, brain imaging, specialist opinions (eg. radiologist, surgeon), conventional karyotype with a resolution of 550 bands for aploid set [11] and a-CGH results (number, type, size, inheritance of CNVs).

\section{Array-CGH analysis}

The Agilent $44 \mathrm{~K}$ platform was used for the analysis of all patients, following manufacturer's instructions (Agilent Technologies). Briefly, $500 \mathrm{ng}$ of patient and control DNAs were double-digested with restriction enzymes (AluI and RsaI) and differentially labeled with Cy-5 and Cy-3, respectively. A "loop" strategy with three phenotypically different patients was used (for example A vs. $\mathrm{B}, \mathrm{B}$ vs. $\mathrm{C}$ and $\mathrm{C}$ vs. A). After hybridization on the $44 \mathrm{~K}$ array, slides were washed and scanned. Agilent Feature Extraction and Genomic Workbench softwares were used to calculate log ratios, to create a graphical visualization of the results and to call copy number aberrations (ADM-1 algorithm - threshold 6.0 -). Changes of 3 or more consecutive oligonucleotides with the same log ratio (deletions about -1 or duplications about +0.5 ) were called as CNVs. The loop strategy allowed the simultaneous confirmation of each $\mathrm{CNV}$, which had to be present in two arrays of the loop with opposite values of log ratio and the elimination of most of the polymorphic CNVs with high frequency in the population.

CNVs were compared to the DECIPHER, DGV, ISCA (International Standard for Cytogenomic Arrays consortium, https://www.iscaconsortium.org/index.php/search) and Troina Database of Human CNVs (http://gvarianti. homelinux.net/gvariantib37/index.php) and classified pathogenic, likely pathogenic, benign, likely benign or of unknown significance, using the following criteria:

- pathogenic: anomalies mapping on genomic regions associated to known syndromes or involving known dosage-sensitive genes and large imbalances of $d e$ novo origin or inherited from a similarly affected parent;

- likely pathogenic: small alterations of de novo origin or inherited from a parent with a similar phenotype, involving genomic regions or genes whose possible association with clinical conditions has not been definitely identified, but could be supposed from the clinical databases (DECIPHER, ISCA and Troina);

- benign: polymorphic variants reported in several healthy individuals in more than one study within DGV and/or alterations detected in at least two patients with clearly distinct phenotypes of the present cohort;

- likely benign: microdeletions and microduplications reported in few controls in DGV, but defined benign or likely benign in the clinical databases 
(DECIPHER, ISCA and Troina) and inherited from a normal parent;

- of unknown significance: inherited alterations not described or with discordant definitions among those databases [12].

\section{Statistical analysis}

Patients were stratified according to the presence of several clinical features, all potentially related to the presence of a pathological phenotype (positive family history, delivery before 37 gestational weeks, apgar score $<7$, low birth weight - less than the fifth centile-, early onset of symptoms ( $<1$ year of age), motor delay, dysmorphisms, malformations -brain excluded-, speech delay, epilepsy, cerebral malformations), converting descriptive variables into numerical. For the purposes of the analysis pathogenic and likely pathogenic CNVs were grouped together. The relationship between each variable and the presence of pathogenic CNVs was first analyzed by means of univariate analysis (chi-squared for 2-by-2 tables). Furthermore, in order to identify the independent predictors of the diagnosis of pathogenic $\mathrm{CNVs}$, the variables resulting significant at the univariate analysis were subjected to logistic regression, using the presence of pathogenic CNVs as a dependent dichotomous variable [13], and odds ratios and their $95 \%$ confidence intervals (CI) were calculated. Results were considered statistically significant for $\mathrm{p}<0.05$. Statistical analyses were carried out with STATA software (version 11.1, 2010; StataCorp, College Station, TX, USA).

The study was approved by Modena Institutional Review Board (Protocol No. 249/12, ${ }^{\text {th }}$ March 2013).

\section{Results}

Out of the 116 patients (58 males and 58 females) subjected to a-CGH analysis, 111 had a normal and 5 an abnormal karyotype (in those latter cases a-CGH was used to characterize the genomic alteration). Abnormal karyotypic findings are listed in Table 1.

Table 2 shows the number, type, inheritance and clinical interpretation of the CNVs found in the study population: 41 patients showed at least one $\mathrm{CNV}$, whereas 75 did not

\begin{tabular}{|c|c|}
\hline Patient No. & Karyotype \\
\hline 5 & $47, X X, \operatorname{del}(6)(q 24),+\operatorname{mar}[30] / 46, X X, \operatorname{del}(6)(q 24)[15]$ \\
\hline 12 & $45, X Y, t(5 ; 15)(p 15.3 ; q 11.2)$ \\
\hline 25 & $46, X Y, \operatorname{dup}(19)(q 12 q 13.2)$ \\
\hline 6 & $46, X Y, \operatorname{der}(9) t(1 ; 9)(q 41 ; q 34)$ \\
\hline 26 & $46, X Y, r(22) . i s h$ del(22q13) \\
\hline
\end{tabular}

For their a-CGH results refer to Table 3 .
Table 2 Type, number, size and inheritance of the CNVs found according to the clinical interpretation

\begin{tabular}{|c|c|c|c|}
\hline \multirow[t]{2}{*}{ Variable } & \multirow{2}{*}{$\begin{array}{l}\text { Patients with } \\
\text { pathogenic CNVs } \\
\mathrm{N}=27\end{array}$} & \multirow{2}{*}{$\begin{array}{l}\text { Patients with } \\
\text { benign CNVs } \\
\mathrm{N}=12\end{array}$} & \multirow{2}{*}{$\begin{array}{l}\text { Patients with } \\
\text { unknown CNVs } \\
\mathrm{N}=2\end{array}$} \\
\hline & & & \\
\hline \multicolumn{4}{|l|}{ Type } \\
\hline Deletion & 21 (77.8\%) & $2(16.7 \%)$ & \\
\hline Duplication & $3(11.1 \%)$ & 9 (75.0\%) & $2(100 \%)$ \\
\hline $\begin{array}{l}\text { Duplication and } \\
\text { deletion }\end{array}$ & 3 (11.1\%) & 1 (8.3\%) & \\
\hline \multicolumn{4}{|l|}{ No. CNVs } \\
\hline 1 & 22 & 8 & 2 \\
\hline$\geq 2$ & 5 & 4 & \\
\hline \multicolumn{4}{|l|}{ Size } \\
\hline$\leq 0.5 \mathrm{Mb}$ & & $6(50 \%)$ & $2(100 \%)$ \\
\hline$>0.5 \mathrm{Mb}$ & 27 (100\%) & $6(50 \%)$ & \\
\hline \multicolumn{4}{|l|}{ Inheritance } \\
\hline De novo & 21 (77.8\%) & $1(8.3 \%)$ & \\
\hline Familial & $5(18.5 \%)$ & 7 (58.3\%) & $2(100 \%)$ \\
\hline Unknown & 1 (3.7\%) & $4(33.3)$ & \\
\hline
\end{tabular}

show any. Twenty-seven out of 41 patients carried a pathogenic (or likely pathogenic) CNV, whereas 12 had a benign one. In 2 unrelated cases (both had a $489 \mathrm{~Kb}$ duplication in 15q13.3 of maternal inheritance) the role of the $\mathrm{CNV}$ found is unknown. The genomic details of the pathogenic CNVs and their clinical correlates are listed in Table 3.

By comparing the frequency of each clinical feature in patients with pathogenic vs. those with benign or absent CNVs (the 2 cases with CNVs of unknown interpretation were excluded), a statistically significant association with the presence of pathogenic CNVs was found for the early onset of symptoms $(p=0.027)$, the presence of dysmorphisms $(\mathrm{p}=0.003)$ and malformations $(\mathrm{p}=0.0001)$, whereas all the other variables did not show any statistical significance (Figure 1).

The clinical variables found to be associated with pathogenic CNVs were further analyzed by a multivariate analysis and a statistically significant odds ratio for association with pathogenic CNVs was confirmed for the presence of dysmorphisms $(\mathrm{p}=0.023)$ and malformations $(p=0.002)$, whereas the onset of symptoms before the first year of age was not $(\mathrm{p}=0.069)($ Table 4$)$.

\section{Discussion}

The use of a-CGH in the clinical settings has been shown to improve the follow-up, the rehabilitation strategies and, in selected cases, the prophylactic therapy in patients in which the presence of pathogenic CNVs is demonstrated $[17,18]$. 
Table 3 List of genomic rearrangements in patients with pathogenic CNVs

\begin{tabular}{|c|c|c|c|c|c|c|c|}
\hline Patient No. & Sex & Type & Locus & Genomic coordinates & Inheritance & Syndrome & OMIM \\
\hline 1 & M & del & $1 p 36.33 p 36.31$ & chr1:837,491-6,458,739 & de novo & 1p36.33 deletion $\mathrm{S}$. & 607872 \\
\hline 2 & $\mathrm{~F}$ & del & 1p36.33p36.31 & chr1:544,268-5,983,997 & de novo & 1 p36.33 deletion S. & 607872 \\
\hline \multirow[t]{2}{*}{3} & $\mathrm{~F}$ & del & $1 p 36.22 p 36.13$ & chr1:11,722,823-17,104,536 & de novo & - & \\
\hline & & del & $1 \mathrm{p} 35.1 \mathrm{p} 34.1$ & $\operatorname{chr1}: 31,080,722-32,355,071$ & de novo & - & \\
\hline 4 & $\mathrm{~F}$ & del & $1 \mathrm{q} 23.3 \mathrm{q} 24.2$ & chr:162,345,741-169,317,061 & de novo & - & \\
\hline \multirow[t]{2}{*}{5} & $\mathrm{~F}$ & del & $1 q 41$ & chr1:217,316,641-218,402,514 & not known & 1q41-1q42 deletions. & 612530 \\
\hline & & del & $6 q 24.2$ & chr6:144,223,274-144,446,997 & not known & - & \\
\hline $6 \operatorname{Ref}[14]$ & M & dup & 1q42qter & chr1:223,858,274-248,105,710 & de novo & - & \\
\hline 7 & $\mathrm{~F}$ & del & $2 q 14.3$ & chr2:125,049,268-129,322,082 & de novo & - & \\
\hline 8 & $\mathrm{~F}$ & del & $2 q 24.3$ & chr2:166,198,780-166,930,047 & de novo & - & \\
\hline \multirow[t]{2}{*}{9} & M & dup & 4p15.32 & chr4:26,509-27,414 & de novo & - & \\
\hline & & del & $17 q 24.2$ & chr17:64,682,538-65,991,538 & de novo & - & \\
\hline 10 & M & del & $4 q 26 q 28.1$ & chr4:117,685,833-127,471,713 & de novo & - & \\
\hline \multirow[t]{2}{*}{11} & M & dup & $4 q 33 q 35.1$ & chr4:171,936,073-186,883,667 & de novo & - & \\
\hline & & del & $4 q 35.1 q 35.2$ & chr4:186,913,016-190,976,417 & de novo & - & \\
\hline $12 \operatorname{Ref}[15]$ & M & del & 5p15.33p15.32 & chr5:22,178-5,539,182 & paternal & Cri du Chat S. & 123450 \\
\hline 13 & $\mathrm{~F}$ & del & $5 q 14.3 q 15$ & chr5:89,535,781-92,554,566 & de novo & - & \\
\hline 14 & M & del & $5 q 23.2 q 31.1$ & chr5:124,391,181-134,632,894 & de novo & - & \\
\hline 15 & $\mathrm{~F}$ & del & $6 q 27$ & chr6:168,378,740-169,862,121 & de novo & - & \\
\hline 16 & M & del & $7 q 11.23$ & chr7:72,039,051-73,771,238 & de novo & Williams-Beuren S. & 194050 \\
\hline 17 & M & del & $7 q 21.13 q 21.3$ & chi7:89,993,838-96,278,971 & de novo & $\begin{array}{l}\text { Split Hand Foot Malformation } 1 \\
\text { with sensorineural hearing loss }\end{array}$ & 220600 \\
\hline 18 & M & del & $7 q 31.1 q 31.2$ & chr7:113,824,764-115,669,764 & de novo & - & \\
\hline 19 & $\mathrm{~F}$ & del & $7 q 36$ & chr7:153,669,067-159,107,239 & de novo & Holoprosencephaly-3 & 142945 \\
\hline 20 & $\mathrm{~F}$ & del & $15 q 13.2 q 13.3$ & chr15:31,014,000-32,510,000 & maternal & - & \\
\hline 21 & $\mathrm{~F}$ & del & $15 q 26.3$ & chr15:99,836,103-102,351,195 & paternal & 15q26-qter deletion S. & 612626 \\
\hline 22 & $\mathrm{~F}$ & dup & $16 \mathrm{p} 13.11 \mathrm{p} 12.3$ & chr16:15,492,317-17,804,366 & maternal & - & \\
\hline 23 & $\mathrm{~F}$ & del & $17 q 12$ & chr17:31,891,355-33,726,698 & de novo & $17 q 12$ deletion $S$ & 614527 \\
\hline 24 & M & del & $19 p 13.3$ & chr19:64,447-721,353 & de novo & - & \\
\hline $25 \operatorname{Ref}[16]$ & M & dup & $19 q 12 q 13.2$ & chr19:28,272,160-40,699,160 & de novo & - & \\
\hline \multirow[t]{2}{*}{26} & M & del & $22 q 13.31$ & chr22:45,576,757-51,178,264 & de novo & Phelan Mc Dermid S. & 606232 \\
\hline & & dup & Xq28 & chrX:153,322,653-153,406,233 & de novo & - & \\
\hline 27 & $\mathrm{~F}$ & del & $22 q 11.21$ & chr22:19,375,985-21,382,953 & maternal & DiGeorge S. & 188400 \\
\hline
\end{tabular}

Genomic coordinates refer to Human Genome Assembly ( $\mathrm{Hg} 19$ ). If the analysis was performed with previous assemblies, data were converted in $\mathrm{Hg} 19 . \mathrm{M}=$ male, $\mathrm{F}=$ female, del = deletion, dup = duplication.

Although the utility is already proven, the Health Care System of the Emilia-Romagna Region has introduced a-CGH in the list of reimbursable tests only in 2013 and the network of laboratories in the Region is still organizing to offer the analysis with short waiting lists and lead times. For all these reasons, understanding which patients and families may benefit the most is required and clinical predictors are needed. Although evidence already exists to offer a-CGH as a first-tier exam in patients showing ID with or without additional clinical features [1], further data have shown that patients with syndromic ID (multiple congenital anomalies) or with severe phenotypes have a higher likelihood to be carriers of CNVs [10].

In our study, the relative burden conveyed by each feature accompanying DD/ID was evaluated by a multivariate analysis on 116 patients in which the frequency of several clinical variables referring to the pregnancy, delivery, family history, associated malformations, psychomotor development and dysmorphisms were compared between patients showing pathogenic CNVs vs. all the others (those negative and with benign CNVs). 


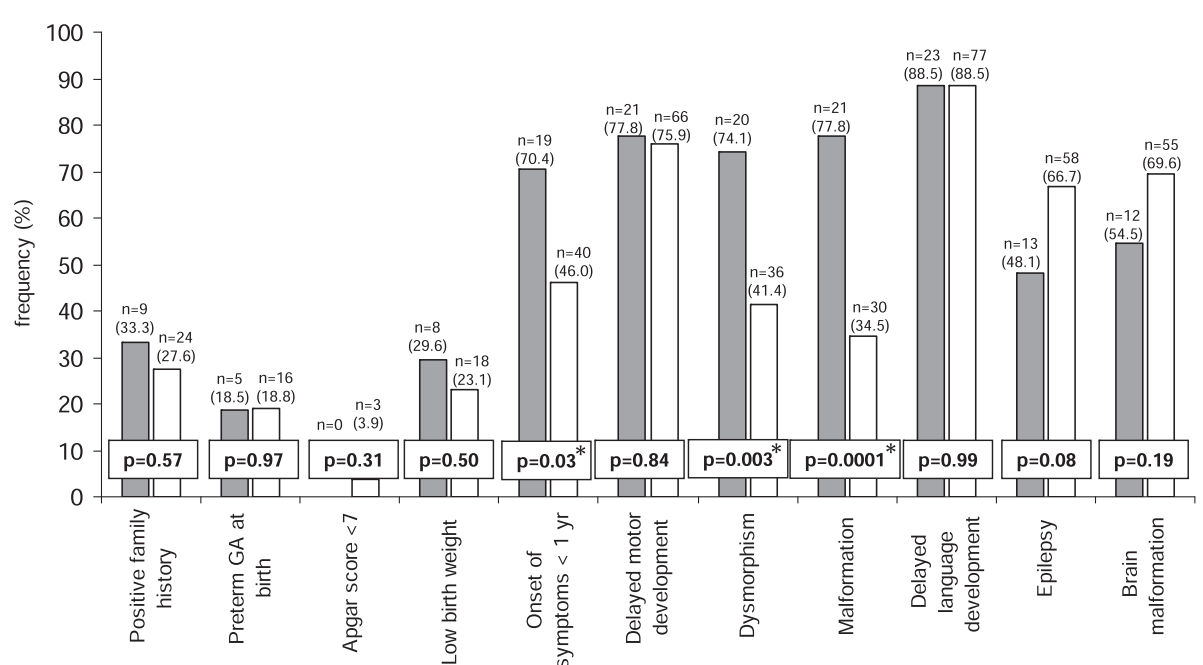

Figure 1 Clinical features of the patients under study according to the presence of pathogenic CNVs. For each variable the number ( $n=)$, the percentage of patients (in parenthesis) and the $\mathrm{P}$ values (in boxes) are reported. Statistical significance is indicated with the presence of an asterisk.

CNVs were detected in 41 out of 116 patients (35.3\%) and a pathogenic role was attributed in 27 cases $(23.3 \%$ of the study population). Among those latter, 21 had a de novo rearrangement, 5 were inherited (Table 3) (the transmitting parent always displayed some degree of phenotype) and 1 was of unknown origin. On the other hand, among the benign CNVs carriers only 1 patient presented a de novo rearrangement, a $500 \mathrm{~Kb}$ interstitial duplication in 14q11.2 of unequivocal interpretation, due to the high frequency $(>3 \%)$ in the normal population [19]. Deletions were $85 \%$ of the pathogenic CNVs, consistent with the notion that haploinsufficiencies are less tolerated than duplications in the human genome [20].

When analysing the clinical features associated with $\mathrm{DD} / \mathrm{ID}$ and their relative frequency in patients with or without pathogenic CNVs, no difference emerged for birth-related variables, delay in motor or language development or for brain malformations and epilepsy (Figure 1), which are possibly attributable also to different aetiologies (i.e. monogenic or multifactorial), due to their high genetic heterogeneity. On the other hand, the onset of symptoms

\begin{tabular}{|c|c|c|c|c|}
\hline Clinical variables & Odds ratio & Std. Err. & $P$ & $\begin{array}{l}\text { [95\% conf. } \\
\text { interval] }\end{array}$ \\
\hline $\begin{array}{l}\text { Early onset of symptoms } \\
\text { (before } 1 \mathrm{yr} \text { of age) }\end{array}$ & 2.567 & 1.331 & 0.069 & $0.930-7.090$ \\
\hline Dysmorphisms & 3.326 & 1.752 & 0.023 & $1.184-9.340$ \\
\hline Malformations & 5.365 & 2.871 & 0.002 & $1.880-15.312$ \\
\hline
\end{tabular}

before one year of life $(\mathrm{p}=0.027)$, the presence of malformations $(\mathrm{p}=0.0001)$ and of dysmorphisms $(\mathrm{p}=0.003)$ resulted significantly associated to the pathogenic CNVs at the univariate analysis (Figure 1), confirming previous data referred to other European populations [10]. When subjected to logistic regression analysis, the dysmorphisms $(p=0.023)$ and the malformations $(p=0.002)$ emerged as independent predictors of diagnosing a pathogenic $\mathrm{CNV}$ in children with DD/ID, whereas the early onset of symptoms, an additional indicator of the gravity of the phenotype encompassing neonatal hypotonia, infantile epilepsy and motor delay, failed to show a significant result, possibly due to a type 2 statistical error caused by the low number of observations.

Our results confirm that severe phenotypes characterized by the presence of malformations and dysmorphisms associated with DD/ID are causally related to the presence of CNVs, as previously demonstrated [10,21]; moreover, the analysis predicts the likelihood to detect a pathogenic genomic alteration, attributing a 3.3-fold increase to the presence of dysmorphic features and a 5.3-fold to the malformations (Table 4), thus reaffirming the importance of a thorough phenotypic characterization of the patients undergoing a-CGH analysis for maximizing the results [10].

\section{Conclusions}

In conclusion, dissecting the phenotype of children with DD/ID undergoing a-CGH led us to identify the malformations and the dysmorphisms as independent clinical predictors for finding pathogenic CNVs, indicating that 
the presence of those features in association with DD/ID should address a-CGH analysis as a high-priority test for diagnosis.

\section{Competing interests}

The authors declare that they have no competing interests.

\section{Authors' contributions}

EC collected the data, organized the database, participated in data analysis; IS drafted the manuscript, participated in data analysis and critical discussion; PM, MGG, SS, TG, PB participated in data collection; AG, PP participated in critical discussion, AP conceived the study, participated in data analysis, manuscript drafting and critical discussion. All authors approved the final version of the manuscript.

\section{Author details}

${ }^{1}$ Pediatrics Unit, Department of Mother \& Child, University Hospital of Modena, Modena, Italy. ${ }^{2}$ Medical Genetics Unit, Department of Mother \& Child, University Hospital of Modena, Via del Pozzo, 71, 41124 Modena, Italy. ${ }^{3}$ Medical Genetics Unit, Department of Medical and Surgical Sciences, University of Bologna, Bologna, Italy. ${ }^{4}$ Mendel Laboratory, IRCCS "Casa Sollievo della Sofferenza" Hospital, S. Giovanni Rotondo, Italy. ${ }^{5}$ Pediatrics Unit, B. Ramazzini Hospital, Carpi, Italy.

Received: 21 November 2013 Accepted: 14 April 2014 Published: 28 April 2014

\section{References}

1. Miller DT, Adam MP, Aradhya S, Biesecker LG, Brothman AR, Carter NP, Church DM, Crolla JA, Eichler EE, Epstein CJ, Faucett WA, Feuk L, Friedman JM, Hamosh A, Jackson L, Kaminsky EB, Kok K, Krantz ID, Kuhn RM, Lee C, Ostell JM, Rosenberg C, Scherer SW, Spinner NB, Stavropoulos DJ, Tepperberg JH, Thorland EC, Vermeesch JR, Waggoner DJ, Watson MS, et al: Consensus statement: chromosomal microarray is a first-tier clinical diagnostic test for individuals with developmental disabilities or congenital anomalies. Am J Hum Genet 2010, 86:749-764.

2. Ahn JW, Bint S, Bergbaum A, Mann K, Hall RP, Ogilvie CM: Array CGH as a first line diagnostic test in place of karyotyping for postnatal referrals results from four years' clinical application for over 8,700 patients. Mol Cytogenet 2013, 6(1):16.

3. Cooper GM, Coe BP, Girirajan S, Rosenfeld JA, Vu TH, Baker C, Williams C, Stalker H, Hamid R, Hannig V, Abdel-Hamid H, Bader P, McCracken E, Niyazov D, Leppig K, Thiese H, Hummel M, Alexander N, Gorski J, Kussmann J, Shashi V, Johnson K, Rehder C, Ballif BC, Shaffer LG, Eichler EE: A copy number variation morbidity map of developmental delay. Nat Genet 2011, 43:838-846.

4. Prince $\mathrm{E}$, Ring $\mathrm{H}$ : Causes of learning disability and epilepsy: a review. Curr Opin Neurol 2011, 24(2):154-158.

5. Girirajan S, Johnson RL, Tassone F, Balciuniene J, Katiyar N, Fox K, Baker C, Srikanth A, Yeoh KH, Khoo SJ, Nauth TB, Hansen R, Ritchie M, Hertz-Picciotto I, Eichler EE, Pessah IN, Selleck SB: Global increases in both common and rare copy number load associated with autism. Hum Mol Genet 2013, 22(14):2870-2880.

6. Redon $R$, Ishikawa S, Fitch KR, Feuk L, Perry GH, Andrews TD, Fiegler H, Shapero MH, Carson AR, Chen W, Cho EK, Dallaire S, Freeman JL, González JR, Gratacòs M, Huang J, Kalaitzopoulos D, Komura D, MacDonald JR, Marshall CR, Mei R, Montgomery L, Nishimura K, Okamura K, Shen F, Somerville MJ, Tchinda J, Valsesia A, Woodwark C, Yang F, et al: Global variation in copy number in the human genome. Nature 2006, 444(7118):444-454.

7. Riggs E, Wain K, Riethmaier D, Smith-Packard B, Faucett W, Hoppman N, Thorland E, Patel V, Miller D: Chromosomal microarray impacts clinical management. Clin Genet 2014, 85:147-153.

8. Girirajan S, Brkanac Z, Coe BP, Baker C, Vives L, Vu TH, Shafer N, Bernier R, Ferrero GB, Silengo M, Warren ST, Moreno CS, Fichera M, Romano C, Raskind WH, Eichler EE: Relative burden of large CNVs on a range of neurodevelopmental phenotypes. PLoS Genet 2011, 7(11):e1002334.

9. Girirajan S, Rosenfeld JA, Coe BP, Parikh S, Friedman N, Goldstein A, Filipink RA, McConnell JS, Angle B, Meschino WS, Nezarati MM, Asamoah A, Jackson KE, Gowans GC, Martin JA, Carmany EP, Stockton DW, Schnur RE, Penney LS, Martin DM, Raskin S, Leppig K, Thiese H, Smith R, Aberg E, Niyazov DM,
Escobar LF, El-Khechen D, Johnson KD, Lebel RR, et al: Phenotypic heterogeneity of genomic disorders and rare copy-number variants. N Engl J Med 2012, 367(14):1321-1331.

10. Vulto-van Silfhout AT, Hehir-Kwa JY, van Bon BW, Schuurs-Hoeijmakers JH, Meader S, Hellebrekers CJ, Thoonen IJ, de Brouwer AP, Brunner HG, Webber C, Pfundt R, de Leeuw N, de Vries BB: Clinical significance of de novo and inherited copy number variation. Hum Mutat 2013, 34(12):1679-1687.

11. ISCN: An international system for human cytogenetic nomenclature (2013) recommendations of the international standing committee on human cytogenetic nomenclature; 2013. Edited by: Shaffer L.G. (Spokane, Wash.), McGowan-Jordan J. (Ottawa, Ont.), Schmid M. (Würzburg).

12. Kearney HM, Thorland EC, Brown KK, Quintero-Rivera F, South ST, Working Group of the American College of Medical Genetics Laboratory Quality Assurance Committee: American College of Medical Genetics standards and guidelines for interpretation and reporting of postnatal constitutional copy number variants. Genet Med 2011, 13(7):680-685.

13. Engelman L: Stepwise logistic regression. In BMDP statistical software manual. Edited by Dixon WJ. Berkeley, CA: University of California Press; 1990:1013-1046.

14. Percesepe A, Lugli L, Pierluigi M, Cavani S, Malacarne M, Roversi MF, Ferrari F, Forabosco A: Pure segmental trisomy 1q42-qter in a boy with a severe phenotype. Am J Med Genet A 2007, 143A(19):2339-2342.

15. Elmakky A, Carli D, Lugli L, Torelli P, Guidi B, Falcinelli C, Fini S, Ferrari F, Percesepe A: A three-generation family with terminal microdeletion involving 5p15.33-32 due to a whole-arm 5;15 chromosomal translocation with a steady phenotype of atypical cri du chat syndrome. Eur J Med Genet 2014, 5(4):145-150.

16. Lugli L, Malacarne M, Cavani S, Pierluigi M, Ferrari F, Percesepe A: A 12.4 Mb direct duplication in 19q12-q13 in a boy with cardiac and CNS malformations and developmental delay. J App/ Genet 2011, 52(3):335-339.

17. Ellison JW, Ravnan JB, Rosenfeld JA, Morton SA, Neill NJ, Williams MS, Lewis J, Torchia BS, Walker C, Traylor RN, Moles K, Miller E, Lantz J, Valentin C, Minier SL, Leiser K, Powell BR, Wilks TM, Shaffer LG: Clinical utility of chromosomal microarray analysis. Pediatrics 2012, 130(5):e1085-e1095.

18. Superti-Furga A, Garavelli L: Current themes in molecular pediatrics: molecular medicine and its applications. Ital J Pediatr 2010, 36:20.

19. Zogopoulos G, Ha KC, Naqib F, Moore S, Kim H, Montpetit A, Robidoux F, Laflamme P, Cotterchio M, Greenwood C, Scherer SW, Zanke B, Hudson TJ, Bader GD, Gallinger S: Germ-line DNA copy number variation frequencies in a large North American population. Hum Genet 2007, 122(3-4):345-353.

20. Brewer C, Holloway S, Zawalnyski P, Schinzel A, FitzPatrick D: A chromosomal duplication map of malformations: regions of suspected haplo- and triplolethality-and tolerance of segmental aneuploidy-in humans. Am J Hum Genet 1999, 64(6):1702-1708.

21. Shoukier M, Klein N, Auber B, Wickert J, Schröder J, Zoll B, Burfeind P, Bartels I, Alsat EA, Lingen M, Grzmil P, Schulze S, Keyser J, Weise D, Borchers M, Hobbiebrunken E, Röbl M, Gärtner J, Brockmann K, Zirn B: Array CGH in patients with developmental delay or intellectual disability: are there phenotypic clues to pathogenic copy number variants? Clin Genet 2013, 83(1):53-65

\section{doi:10.1186/1824-7288-40-39}

Cite this article as: Caramaschi et al:: Predictive diagnostic value for the clinical features accompanying intellectual disability in children with pathogenic copy number variations: a multivariate analysis. Italian Journal of Pediatrics 2014 40:39. 